\title{
Southern-Hemisphere high-latitude stratospheric warming revisit
}

\author{
Yan $\mathrm{Xia}^{1} \cdot$ Weixuan $\mathrm{Xu}^{1} \cdot$ Yongyun $\mathrm{Hu}^{1}$ (1) $\cdot \mathrm{Fei} \mathrm{Xie}^{2}$
}

Received: 7 September 2019 / Accepted: 7 December 2019 / Published online: 18 December 2019

(c) The Author(s) 2019

\begin{abstract}
Previous studies showed significant stratospheric warming at the Southern-Hemisphere (SH) high latitudes in September and October over 1979-2006. The warming trend center was located over the Southern Ocean poleward of the Western Pacific in September, with a maximum trend of about $2.8 \mathrm{~K} / \mathrm{decade}$. The warming trends in October showed a dipole pattern, with the warming center over the Ross and Amundsen Sea, and the maximum warming trend is about $2.6 \mathrm{~K} / \mathrm{decade}$. In the present study, we revisit the problem of the SH stratospheric warming in the recent decade. It is found that the SH highlatitude stratosphere continued warming in September and October over 2007-2017, but with very different spatial patterns. Multiple linear regression demonstrates that ozone increases play an important role in the SH high-latitude stratospheric warming in September and November, while the changes in the Brewer-Dobson circulation contributes little to the warming. This is different from the situation over 1979-2006 when the SH high-latitude stratospheric warming was mainly caused by the strengthening of the Brewer-Dobson circulation and the eastward shift of the warming center. Simulations forced with observed ozone changes over 2007-2017 shows warming trends, suggesting that the observed warming trends over 2007-2017 are at least partly due to ozone recovery. The warming trends due to ozone recovery have important implications for stratospheric, tropospheric and surface climates on SH.
\end{abstract}

Keywords Stratospheric warming $\cdot$ Ozone recovery $\cdot$ Wave-driven dynamic heating $\cdot$ Brewer-Dobson circulation $\cdot$ SST warming

\section{Introduction}

It is well known that the ozone layer experienced depletion in the last quarter of the twentieth century. Especially, severe ozone depletion was found in the Antarctic stratosphere in austral spring, i.e., the so-called Antarctic Ozone Hole. Associated with ozone depletion, the Antarctic stratosphere demonstrated strong cooling trends in austral spring and summer from the late 1970s to the late 1990s (Randel and Wu 1999; Solomon 1999; Thompson and Solomon 2002). It is thought that the cooling trend is mainly caused by the radiative effect of severe ozone depletion (Ramaswamy et al. 2001), and that increasing greenhouse gases also partly

Yongyun $\mathrm{Hu}$

yyhu@pku.edu.cn

1 Laboratory for Climate and Ocean-Atmosphere Studies, Department of Atmospheric and Oceanic Sciences, School of Physics, Peking University, Beijing 100871, China

2 College of Global Change and Earth System Science, Beijing Normal University, Beijing 100875, China contributed to the cooling trends (Langematz et al. 2003) due to their radiatively cooling effects in the stratosphere.

In contrast to the cooling trend, Johanson and $\mathrm{Fu}$ (2007) and $\mathrm{Hu}$ and $\mathrm{Fu}$ (2009) found warming trends over a large portion of the Southern-Hemisphere (SH) high-latitude stratosphere in September and October, and the warming and cooling trends demonstrate a wavenumber 1 pattern. Their results, derived from satellite Microwave Sounding Unit (MSU) observations, show the largest warming of $7-8{ }^{\circ} \mathrm{C}$ in the September and October over the period of 1979-2006. Warming trends are also found at all stratospheric levels in the NCEP/NCAR reanalysis, and the maximum warming is about $11^{\circ} \mathrm{C}$ at 30 and $20 \mathrm{hPa}$. In fact, warming signals can also be identified in earlier works (Ramaswamy et al. 1996; Randel and Wu 1999). However, little attention was paid to the warming trends because all these studies had concentrated on ozone-induced stratospheric cooling.

It is known that polar stratospheric temperatures are determined by both radiative and dynamical processes (Andrews et al. 1987; Hu and Tung 2002). The radiative effects of both ozone depletion and increasing greenhouse 
gases lead to stratospheric cooling. Then, the warming trends are likely a result of wave-driven dynamic heating. Indeed, $\mathrm{Hu}$ and $\mathrm{Fu}$ (2009) demonstrated that the SH high-latitude stratospheric warming is caused by enhanced wave-driven dynamic heating. That is, increasing wave activity caused the strengthening of the Brewer-Dobson circulation (BDC), which consequently leads to stronger downward motion in the polar region and enhanced adiabatic heating in SH high latitudes. They showed that the stratospheric warming trends are closely related to sea surface temperature (SST) warming in the tropical Pacific, and their simulations forced by observed SST demonstrated that increasing wave activity in the SH stratosphere is caused by SST warming. The results by $\mathrm{Hu}$ and $\mathrm{Fu}$ (2009) were further confirmed by Lin et al. (2009, 2012), and Fu et al. (2010, 2015). Especially, they showed how ozone-induced radiative cooling and wavedriven dynamic heating cancel each other and lead to the wavenumber one pattern of stratospheric temperature trends over SH high latitudes. Moreover, the maximum covariance analysis by Lin et al. (2012) showed that the La Nina-like and the central-Pacific El Nino-like SST anomalies result in stronger stratospheric planetary wave activity and phase shifts of the stratospheric stationary waves.

As pointed out by $\mathrm{Hu}$ and $\mathrm{Fu}$ (2009), the warming trends may have important effects on the recovery of the Antarctic ozone hole. First, the warming may reduce the formation of the polar stratospheric clouds, which would consequently reduce ozone depletion in the Antarctic stratosphere. Second, increasing wave activity may cause weakening of the polar vortex or the polar night jet, which would lead to more high-ozone air mixed into the polar region. Both effects would benefit the recovery of the ozone hole.

The most recent report of ozone assessments has pointed out that the ozone hole is recovering (WMO 2018), as a result of the Montreal Protocol. Observations showed that Antarctic ozone has started increasing in the twentyfirst century (Salby et al. 2011; Solomon et al. 2016). A recent study showed satellite observational results of significant recovery of $\mathrm{O}_{3}$ in the lower, middle and upper stratosphere and total column ozone in the Southern-Hemisphere middle and high latitudes (Wespes et al. 2019). It was suggested that zonalmean warming trends in the Antarctic lower stratosphere are associated with ozone recovery, based on results from the reanalysis and simulations by chemistry-climate models (Maycock et al. 2018; Randel et al. 2017; Solomon et al. 2017), although the model studies showed a large spread of trends in polar stratospheric temperatures (Maycock et al. 2018; Thompson et al. 2012). However, Philipona et al. (2018) found that the Antarctic lower stratosphere remains cooling in the twentyfirst century, using four radiosonde stations on the Antarctic. These results imply that there exist zonally non-uniform distributions of temperature trends in the Antarctic lower stratosphere.
The purpose of the present study is to revisit the warming trends in the SH high-latitude stratosphere in the recent decade, using up-to-date satellite observations. Especially, we focus on the spatial patterns of temperature trends. We also preform simulations, with stratospheric ozone forcing, to demonstrate how stratospheric ozone changes in the recent decade generate stratospheric temperature trends.

\section{Data and model setup}

\subsection{Data}

To investigate changes of temperatures in the lower stratosphere (TLS), we use the Advanced Microwave Sounding Units (AMSU) lower stratospheric channel brightness temperature data version 4.0 from 1979 to 2017 (Mears and Wentz 2009). Monthly-mean temperature data, with $2.5^{\circ} \times 2.5^{\circ}$ horizontal resolution, is used in this study (data available at http://www.remss.com/measurements/upper -air-temperature/). Here, TLS is a combination of MSU channel 4 and AMSU channel 9. The weighting function of TLS has peak sensitivities over approximate range of 150-40 hPa (13-22 km) (Young et al. 2011), which can well capture the lower stratospheric condition. The monthly gridded global dataset from the Center for Satellite Applications and Research (STAR) for the National Oceanic and Atmospheric Administration (NOAA) merged the Stratospheric Sounding Unit (SSU) and AMSU-A version 3.0, with resolution of $2.5^{\circ} \times 2.5^{\circ}$, is used to calculate temperature trends in the middle and upper stratosphere (Zou and Qian 2016). The weighting functions of these channels for temperatures in the mid-stratosphere (TMS), upper-stratosphere (TUS), and top-stratosphere (TTS) peak at approximately 10,3 , and $1.5 \mathrm{hPa}$, respectively. The data is available at ftp://ftp.star.nesdis.noaa.gov/pub/ smcd/emb/mscat/data/SSU/SSU_v3.0/.

Monthly mean total column ozone data is from the Multi Sensor Re-analysis version 2 (MSR2) over 1979-2017 (Van Der et al. 2015a, b). The MSR2 is constructed using all available satellite observations, surface Brewer and Dobson observations, with a data assimilation model. It has horizontal resolution of $0.5^{\circ} \times 0.5^{\circ}$. The unit of total column ozone is the Dobson Unit (DU). It is available at http://www.temis .nl/protocols/O3global.html.

ERA-Interim daily reanalysis produced by the European Centre for Medium Range Weather Forecasts (ECMWF) (Dee et al. 2011) is used to calculate eddy heat fluxes. We use the monthly mean data with spatial resolution of $1.5^{\circ} \times 1.5^{\circ}$ from 1979 to 2017 . The data is available at http://apps.ecmwf.int/datasets/data/interim-full-moda/levty $\mathrm{pe}=\mathrm{sfc} /$ ). 


\subsection{GCM experiments}

The model used in the present study is the Whole Atmosphere Community Climate Model (WACCM) (Marsh et al. 2013), which is compiled from the National Center for Atmospheric Research (NCAR) Community Earth System Model version 1.2 (CESM1.2). The specified chemistry WACCM (SC-WACCM) is used to specify ozone concentrations in the atmosphere (Smith et al. 2014). The SCWACCM has horizontal resolution of $1.9^{\circ} \times 2.5^{\circ}$ and 66 vertical levels from the ground to $4.5 \times 10^{-6} \mathrm{hPa}$.

To study the effect of ozone recovery on $\mathrm{SH}$ stratospheric temperatures in the recent decade, we perform two simulations with different ozone prescriptions, while greenhouse gases and SSTs are fixed at 2000. In the control experiment, monthly mean ozone at year 2000 is prescribed (case F_2000_WACCM_SC), and the model is run for 30 years. In the ozone recovery experiment (O3R), output from the control experiment is used as initial conditions, the net ozone change over 2007-2017 is added to the column ozone of year 2000, and the simulation is also run for 30 years. Here, the recovery of total column ozone is obtained from the linear trend over 2007-2017, which is multiplied by 10 years (shown in Fig. 3). The vertical distributions of total column ozone recovery are obtained from the vertical profile used in the reference simulation (REF-B2) of WACCM in the Chemistry-Climate Model Validation (CCMVal-2) (Eyring et al. 2005, 2010). The effects of ozone recovery on stratospheric temperatures can be characterized by the difference between the last 15-year averages of the $\mathrm{O}_{3} \mathrm{R}$ simulation and the control simulation.

\section{Results}

\subsection{Stratospheric temperature and ozone changes}

Figure 1 shows spatial distributions of SH TLS trends in austral spring for 1979-2006 (upper panels), and 2007-2017 (lower panels), derived from satellite observations. The warming trends in upper panels are almost the same as that in $\mathrm{Hu}$ and $\mathrm{Fu}$ (2009) although they are from different MSU/ AMSU datasets. Warming trends in September are located over the sector of western Pacific Ocean (Fig. 1a). Significant warming trends in October are located over the Amundsen Sea and Ross Sea (Fig. 1b), with significant cooling trends over the sector of the Indian Ocean. In November (Fig. 1c), there are only significant cooling trends over the southern Indian Ocean. Warming trends in September and October are about 2.8 and $2.6 \mathrm{~K} /$ decade, respectively. Trends in all the 3 months show a zonal wavenumber one or dipole pattern.
Warming trends are dominant over 2007-2017 in the SH high-latitude stratosphere, except for October. Comparison of TLS trends between periods 2007-2017 and 1979-2006 shows very different spatial patterns. For September, the warming pattern shows a westward shift of about $90^{\circ}$ in longitude (Fig. 1a vs. d). For October, the warming trends are much weaker than that in September and November. The spatial patterns of warming and cooling trends between 2007 and 2017 and 1979-2006 shows a shift of about $180^{\circ}$ in longitude, almost switching locations. For November, the polar region is dominated by large warming trends over 2007-2017, in contrast to the cooling trends over 1979-2006. It is worth pointing out that Fig. 1d, f show large warming trends over 2007-2017, with maximum values of $7 \mathrm{~K} /$ decade and $13 \mathrm{~K} /$ decade in September and November, respectively. Note that trends over the period of 2007-2017 may not be statistical significance because the period is too short.

To demonstrate temperature changes at higher stratospheric levels, we plot trends in TMS, TUS, and TTS over 2007-2017 in Fig. 2. In September, warming trends decrease with altitude, and the area of warming trends becomes smaller with increasing altitude. The spatial patterns of warming trends show westward and poleward tilting. At the same time, cooling trends become stronger and dominant with increasing altitude. In October, all these levels show dominant cooling trends, in contrast to the warming trends at the lower stratosphere. In November, all levels demonstrate warming trends over the sector of western Pacific Ocean. The cooling trends are in the polar region in the upper and top stratosphere, in contrast to the warming trends in the polar region in the lower stratosphere. The vertical structures of temperature trends are consistent with the "mirrored shape" between the lower and upper stratosphere of zonalmean Antarctic stratospheric temperature changes (Solomon et al. 2017).

The above results demonstrate that warming in the $\mathrm{SH}$ high-latitude lower-stratosphere continued in the recent decade. An important question is what caused the warming trends in the recent decade. Previous works have attributed the warming over 1979-2006 to increasing wave-driven dynamic heating in the $\mathrm{SH}$ stratosphere $\mathrm{Hu}$ and $\mathrm{Fu} 2009$; Lin et al. 2009). It is known that Antarctic ozone started increasing since the late 1990s. Whether increasing ozone contributed to the warming trends in the recent decade is the major question that we want to address in the present study. In the following, we first show ozone changes in the recent decade before we perform attribution analysis.

The upper panels in Fig. 3 show spatial distributions of trends in total column ozone over 1979-2006, derived from MSR2. Severe ozone depletion in the Antarctic stratosphere can be clearly seen in Fig. 3a-c. The maximum 

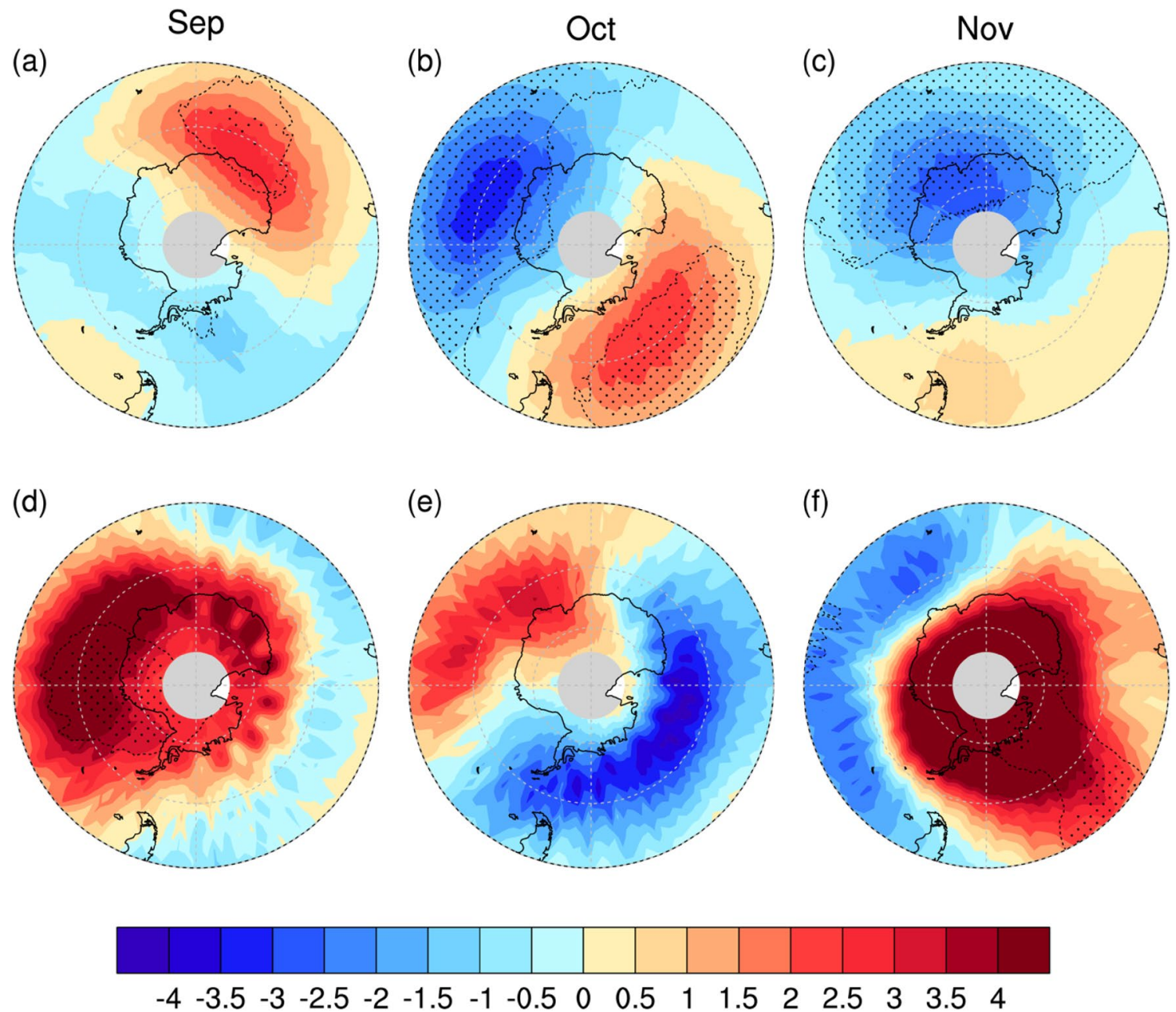

Fig. 1 TLS trends derived from AMSU satellite data. Upper panels: TLS trends over 1979-2006, and lower panels: trends over 20072017. Plots from right to left are for September, October, and November, respectively. Regions with dots are the places where linear trends

ozone decreases are about 42,55 , and 40 DU/decade in September, October, and November, respectively. It is the radiative cooling effect of ozone depletion that contributed to the cooling trends in the Antarctic stratosphere (Fig. 1a-c). The lower panels show ozone increases over 2007-2017. The maximum ozone increase is about 66 and 103 DU over the 10 years in September and November, respectively (Fig. 2d, f). It is important to note that the spatial patterns of the ozone trends well resemble those of the temperature trends for 2007-2017 (Fig. 1d-f). The spatial correlation coefficients between the changes in ozone and lower stratospheric temperature from $45^{\circ} \mathrm{S}$ to $90^{\circ} \mathrm{S}$ are $0.91,0.89$, and 0.99 in September, October, and November, respectively, indicating that the warming trends over 2007-2017 might largely be related to the increase in ozone. are statistically significant at the $95 \%$ confidence level (student $t$ test). The dotted contour lines enclose regions where the trends are significant at the $90 \%$ confidence level. The unit is K/decade

\subsection{Attribution of the TLS trend}

In this section, we perform attribution analysis to reveal what caused the warming trends in recent decade. Following Lin et al. (2009), we use the method of multiple linear regression to attribute the respective contributions of wave-driven dynamic heating, ozone changes, and wave-phase shifts to temperature changes. In Lin et al. (2009), they defined the ozone index as the area-weighted spatial-mean total ozone over $45^{\circ} \mathrm{S}$ poleward to represent the ozone effect on highlatitude stratospheric warming. Here, to better characterize the zonally non-uniform distribution of ozone changes, we define the ozone index for each grid point, which is slightly different from the ozone index in Lin et al. (2009). The highlatitude stratosphere is heated adiabatically by the descending branch of BDC. To denote the strength of the BDC, an "eddy-heat flux index" is defined as the area-weighted 

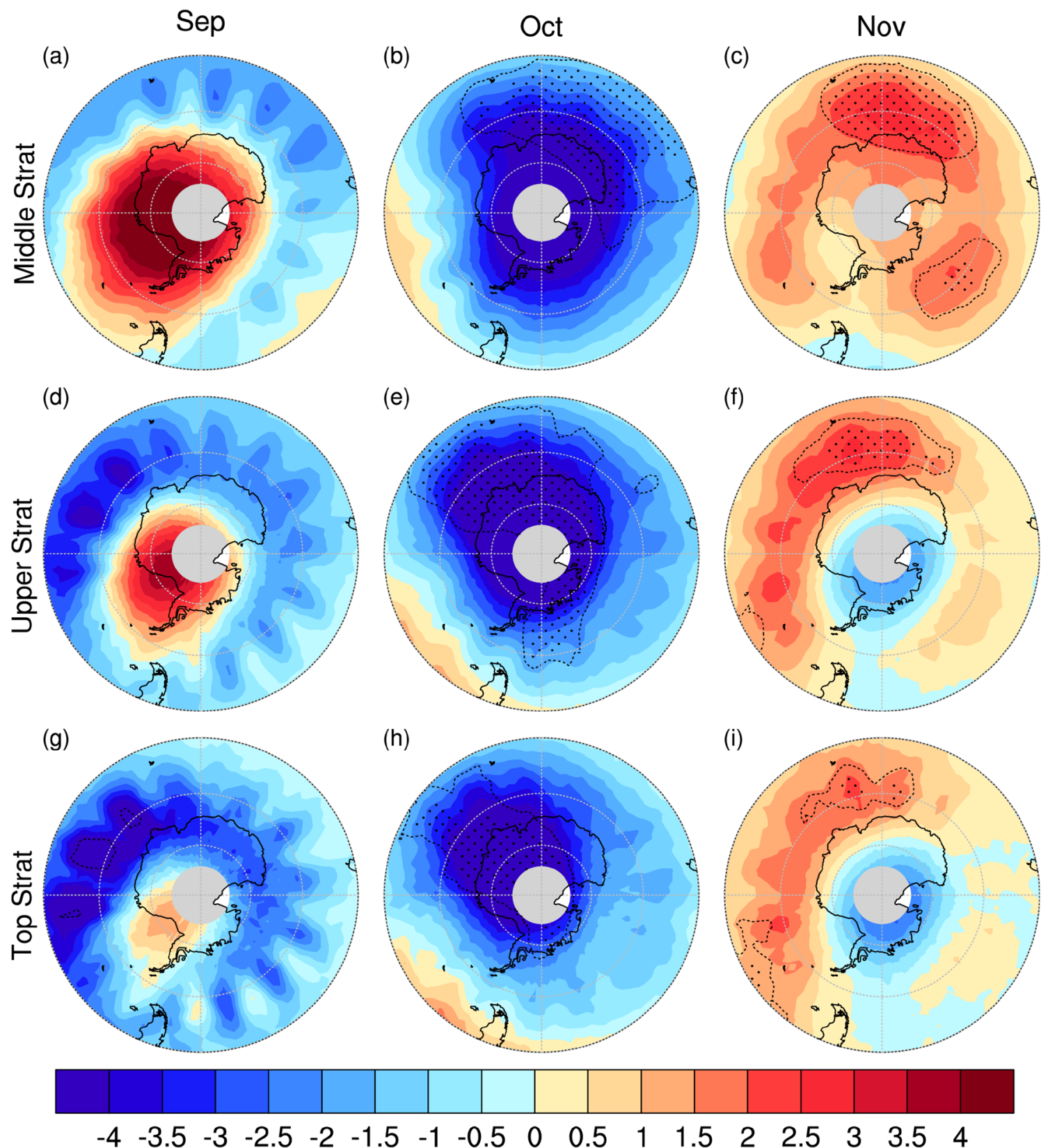

Fig. 2 Temperature trends in the middle, upper, and top stratosphere over 2007-2017, derive from merged SSU and AMSU-A data. Top panels: TMS (SSU channel 1), middle panels: TUS (SSU channel 2), and bottom panels: TTS (SSU channel 3). Regions with dots are the

three-month-mean (including the previous 2 months) eddy heat flux at $150 \mathrm{hPa}$ over $45^{\circ}-90^{\circ} \mathrm{S}$ calculated from the ERA Interim reanalysis. In addition to these, the zonal shift of the wavenumber- 1 phase temperature pattern alters the zonal distribution of temperature trends and thus leads to temperature changes, although it doesn't affect the zonalmean temperature. Thus, we define a "phase index" as the longitude of the largest temperature averaged over $50^{\circ}-70^{\circ}$ $\mathrm{S}$ in the lower stratosphere. places where linear trends have statistically significant levels higher than the 95\% confidence level (student $t$ test). The dotted contour lines enclose regions where the trends are significant at the $90 \%$ confidence level. The unit is $\mathrm{K} /$ decade

Figure 4 shows the time series of area-weighted TLS within the warming area that is enclosed by the contour of $4 \mathrm{~K} /$ decade in September over 2007-2017, together with time series of the eddy-heat flux index, the area-weighted spatial-mean ozone over the warming area that is enclosed by the contour of $4 \mathrm{~K} /$ decade in September over 2007-2017, and the phase index. Linear regression yields a warming trend of about $5.1 \mathrm{~K} /$ decade over 2007-2017 (red line). The eddy-heat flux index shows little increase (blue line), in 

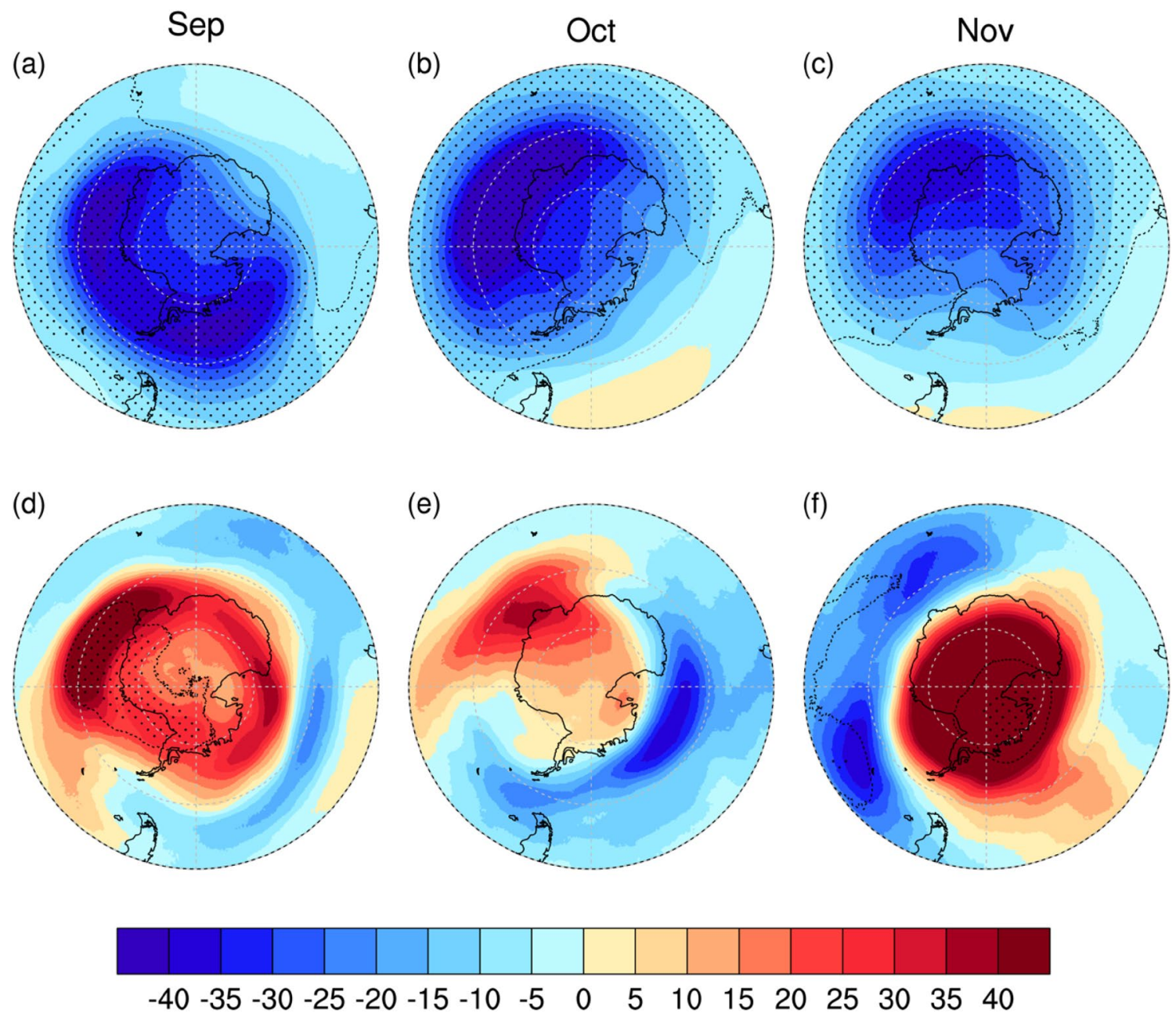

Fig. 3 Similar to Fig. 1, except for trends in total column ozone derived from MSR2. Unit is DU/decade. Upper panels: ozone trends over 1979-2006, and lower panels: ozone trends over 2007-2017.

contrast to the significant positive trend over 1979-2006. The spatial-mean ozone shows an increase by about $37 \mathrm{DU}$ over 2007-2017 (green line), in contrast to the systematic decrease over 1979-2006. The ozone change is consistent with the TLS change. The correlation coefficient between the time series of TLS and ozone is as high as 0.98 over 2007-2017. The phase index shows a westward shift, with a value of $31^{\circ}$ in longitude over the decade (orange line). These results indicate that ozone increase and the phase shift of the wavenumber-1 pattern have the major contribution to the TLS trend, while eddy heat flux has little contribution. We will further address this using multiple linear regressions later.

Figure 5 shows the time series of area-weighted TLS over the warming area enclosed by the contour of $2 \mathrm{~K} /$ decade in October over 2007-2017, the eddy-heat flux index, the area-weighted spatial-mean ozone over the warming area enclosed by the contour of $2 \mathrm{~K} / \mathrm{decade}$ in October over
The period is too short to calculate statistical significance for ozone trends over 2007-2017

2007-2017, and the phase index in October. TLS shows increase over 2007-2017, and its linear trend is about $2.6 \mathrm{~K}$ over the recent decade, about half of that in September. The eddy-heat flux index also shows increasing over the recent decade, but the trend is statistically insignificant. Ozone change is about 22 DU over 2007-2017. The phase index shows a positive trend, about $11^{\circ}$ of eastward shift over the decade. The correlation coefficients between TLS and the eddy-heat flux index, TLS and ozone, and TLS and the phase index are $0.46,0.97$, and -0.41 , respectively. These results suggest that both BDC strengthening and ozone increase may contribute to the warming trends at the $\mathrm{SH}$ high latitudes in October.

Figure 6. shows the time series of these variables in November. TLS shows a significant warming trend over 2007-2017, with a value of about $9.5 \mathrm{~K}$ over the recent decade. It is about twice larger than that in September. The linear trend of eddy-heat fluxes, about $0.49 \mathrm{Km} / \mathrm{s}$, is weak 


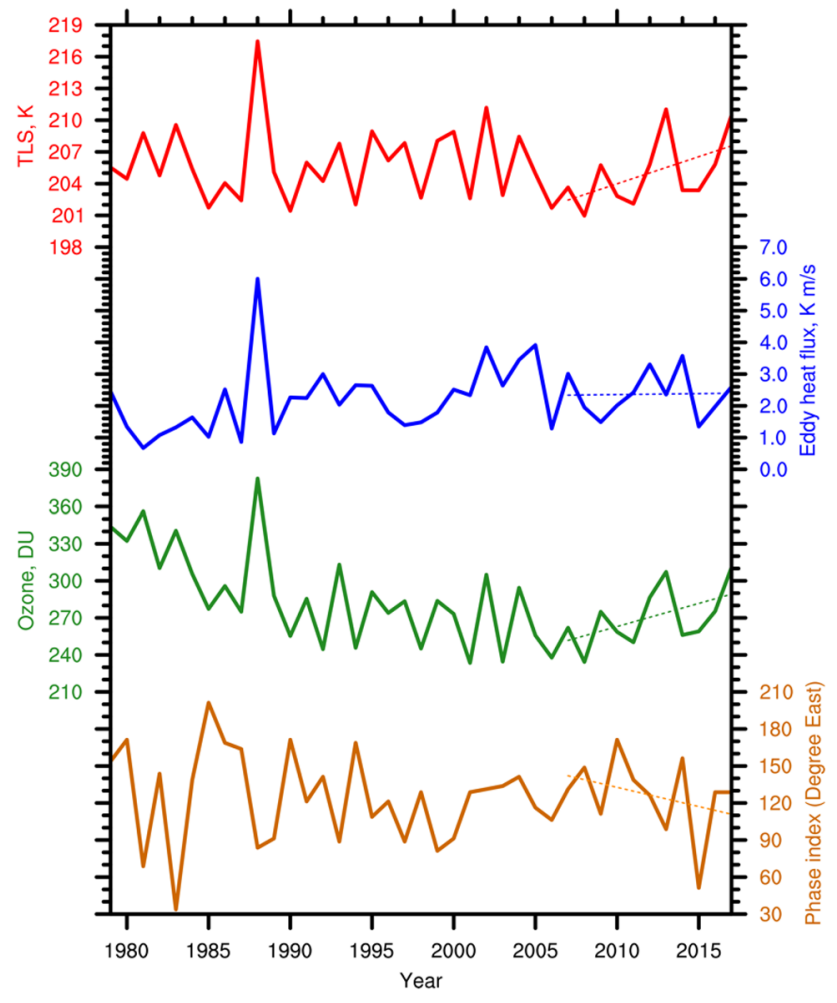

Fig. 4 Time series of area-weighted lower stratospheric temperatures (red) over the warming area enclosed by the contour of $4 \mathrm{~K} /$ decade in September over 2007-2017, eddy heat flux index (blue), the areaweighted spatial-mean ozone over the warming area enclosed by the contour of $4 \mathrm{~K} / \mathrm{dec}$ ade in September over 2007-2017 (green), and the phase index (orange). The dotted lines indicate the corresponding linear trends in the recent decade

and insignificant. The increase of total column ozone is about 70 DU over 2007-2017. The linear trend of ozone is statistically significant at the $90 \%$ confidence level. The phase index shows an insignificant negative trend, about $46^{\circ}$ of westward shift over the decade. The correlation coefficients between TLS and the eddy-heat flux index, TLS and ozone, and TLS and the phase index are 0.64, 0.90 , and 0.39 , respectively. These results suggest that the significant increase of ozone might be the major contribution to the warming trends at the $\mathrm{SH}$ high latitudes in November.

Using the method of multiple linear regression, Lin et al. (2009) attributed TLS warming over 1979-2006 to the BDC strengthening, phase shift of the temperature wavenumber-1 pattern, as well as their cancellation with ozone depletion. Especially, they found that the BDC strengthening played the major role in causing the warming in the SH high-latitude stratosphere over 1979-2006. Following Lin et al. (2009), we carry out multiple linear regression of gridded monthly mean TLS upon the eddyheat flux index, ozone index, phase-shift index, and the

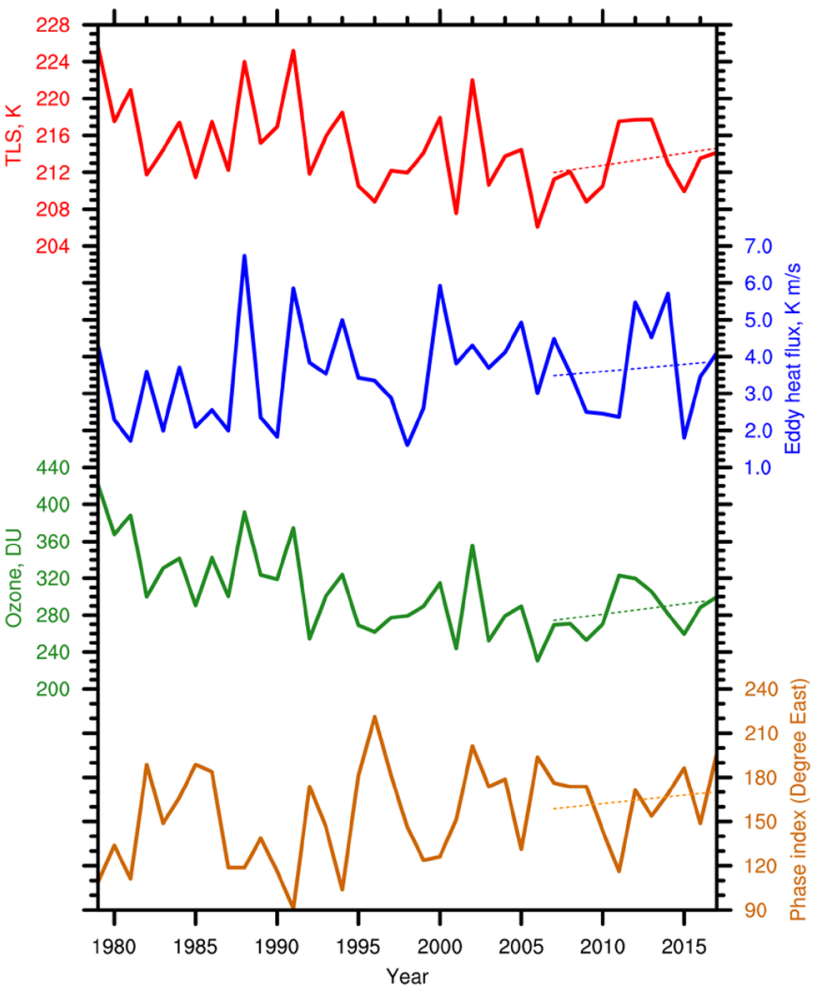

Fig. 5 Time series of area-weighted lower stratospheric temperatures (red) over the warming area enclosed by the contour of $2 \mathrm{~K} / \mathrm{decade}$ in October over 2007-2017, eddy heat flux index (blue), the areaweighted spatial-mean ozone over the warming area enclosed by the contour of $2 \mathrm{~K} / \mathrm{dec}$ ade in October over 2007-2017 (green), and the phase index (orange). The dotted lines indicate the corresponding linear trends in the recent decade

residual term. The contributions to the TLS trend are then obtained by multiplying the regression coefficients by the linear trend in the corresponding indexes.

Figure 7 shows the multiple regression results for September, October, and November over 2007-2017. In September, ozone increase has the largest contribution to the observed TLS warming trend, and the spatial pattern of ozone changes can well capture that of the observed TLS trends. In contrast, both eddy heat flux and phase shift have minor contributions to the TLS trend pattern. The residual term is relatively small. This is consistent with the time series in Fig. 4. In October, it is also ozone changes that have the major contribution to the observed TLS trend pattern, while phase changes have a weak negative contribution. For November, it is the same that ozone increase over the polar region has the major contribution to the polar warming, and that the contributions of the other two terms are negotiable. Overall, the observed TLS trends over 2007-2017 can be well explained by the ozone changes. 


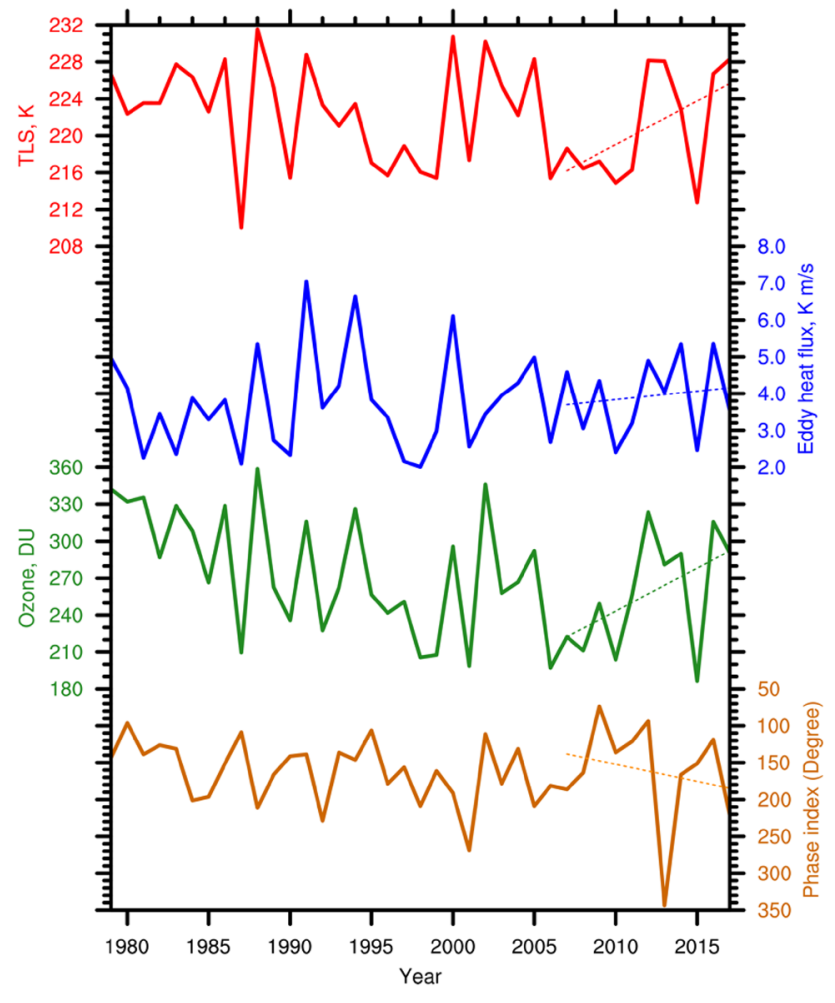

Fig. 6 Time series of area-weighted lower stratospheric temperatures (red line) over the warming area enclosed by the contour of $7 \mathrm{~K} / \mathrm{dec}-$ ade in November over 2007-2017, eddy heat flux index (blue), the area-weighted spatial-mean ozone over the warming area enclosed by the contour of $7 \mathrm{~K} /$ decade in November over 2007-2017 (green), and the phase index (orange). The dotted lines indicate the corresponding linear trends in the recent decade

\subsection{Simulation results}

To further verify the contribution of ozone changes to the observed temperature trends in the recent decade, we carry out simulations as described in Sect. 2. Simulated temperature responses to observed ozone changes over 2007-2017 are shown in Fig. 8. For September (left panels of Fig. 8), the warming trend pattern and its location are close to that in Figs. 1d and 2 (left panels). The warming trends are weaker than observations. The warming trend patterns also show westward and poleward tilting with increasing altitudes, similar to that in Figs. 1d and 2 (left panels). The middle panels of Fig. 8 show weak temperature responses to ozone recovery in October. The simulated warming trends in TLS are rather weak. At higher stratospheric levels, temperature trends become negative. They are consistent with the observational results in Fig. 1e and the middle panels of Fig. 2, but with weaker trends. For November (right panels), simulated TLS trends largely resemble that in Fig. 1f. Temperature trends at higher stratospheric levels also resemble observations in the right panels of Fig. 2. The simulated maximum warming trends in September and November are about 2 and $2.6 \mathrm{~K}$, respectively. In summary, the simulation results demonstrate consistent results with observations, especially in September and November in general, although the simulation cannot reproduce the magnitudes of the observed warming trends.

\section{Discussion and conclusions}

In this study, we have revisited the lower stratospheric warming over SH high latitudes in austral spring found by Johanson and $\mathrm{Fu}$ (2007) and $\mathrm{Hu}$ and $\mathrm{Fu}$ (2009). Updated satellite observations demonstrate that the warming continued in the lower stratosphere in the recent decade, especially in September and November. The maximum warming trends in September and November are up to 7 and $13 \mathrm{~K}$ over 2007-2017, respectively. However, the spatial patterns of temperature trends are largely different from that over 1979-2006. The wavenumber 1 pattern in September shifted by about $90^{\circ}$ in longitude compared to that over 1979-2006, and it shifted by about $180^{\circ}$ in October. In November, warming trends are mainly in the lower stratospheric polar region.

Satellite observations show vertically tilting structures of temperature trends. The warming trends in September title westward and poleward with the increasing altitude. In October, the lower stratospheric shows warming, while the middle and upper stratosphere show cooling trends. For November, large warming trends are found in the lower Antarctic stratosphere, while the polar region becomes cooling with increasing altitudes.

Multiple linear regression shows that ozone recovery in the Antarctic stratosphere plays an important role in causing the observed warming trends over 2007-2017. This is different from that over 1979-2006 when the strengthening of the BDC was the major factor in causing the high-latitude warming (Hu and Fu 2009; Lin et al. 2009). The time series of eddy heat fluxes shows that wave activity had little increase in the recent decade, as shown in Figs. 4 and 5, while the recovery of Antarctic ozone became the major factor that contributed to the observed warming.

Our simulations forced by ozone recovery can reasonably reproduce the spatial patterns of temperature trends, especially in September and November. The simulation results also generate the observed vertically tilting structures of temperature trends at different SH high-latitude stratospheric levels. However, the magnitudes of simulated temperature trends are weaker than observations, the simulation result could not well reproduce the warming trends in October. Thus, the simulation results here suggest that at least part of the high-latitude stratospheric warming trends over 2007-2017 are due to ozone recovery.

Note that it requires further studies to confirm the contribution of ozone recovery on the observed warming trends, 


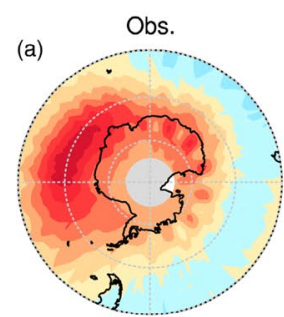

(g)

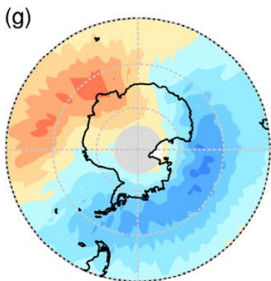

(m)

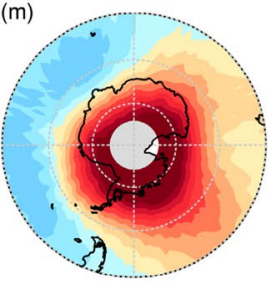

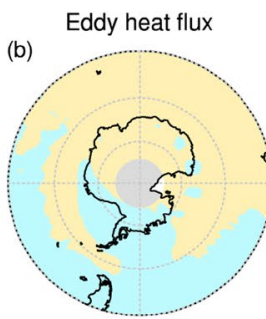

(h)
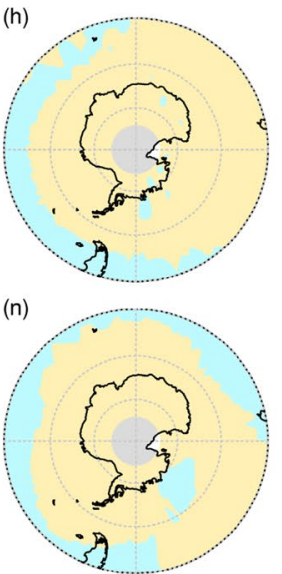

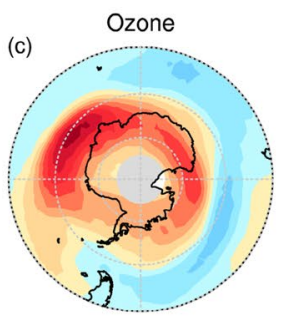

(i)

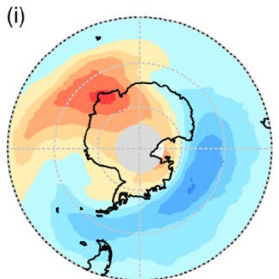

(o)

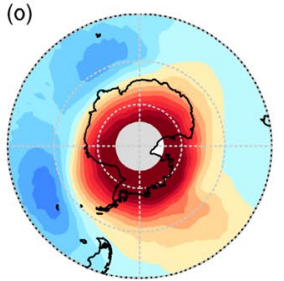

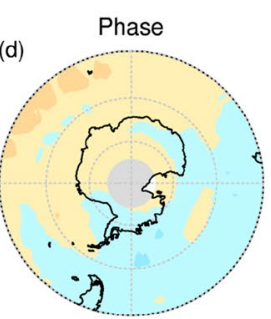

(j)

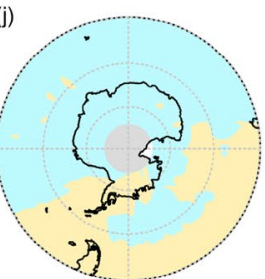

(p)

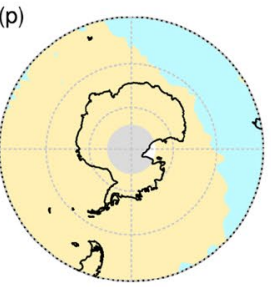

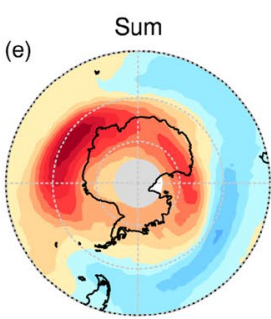

(k)

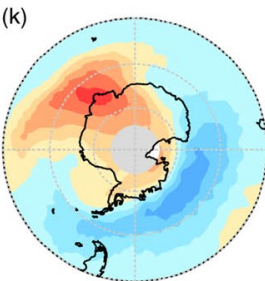

(q)

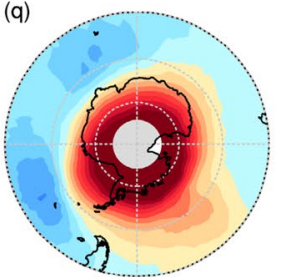

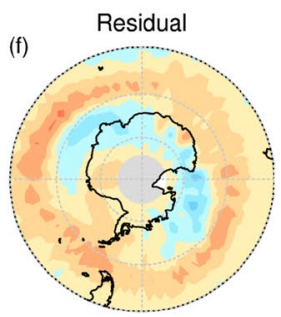

(I)

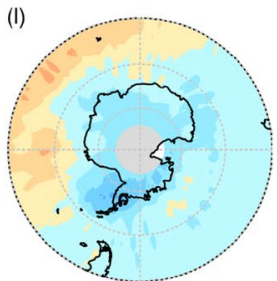

(r)

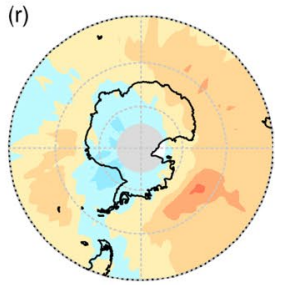

$-8$

Fig. 7 Multiple linear regression of observed TLS trends over 20072017. Top panels: September, middle panels: October, and bottom panels: November. From left to right, the plots are observed TLS trends, TLS trends attributable to the BDC as represented by the eddy heat flux index, TLS trends attributable to ozone index, TLS trends attributable to phase shifts, summation of the three terms, and the residual term, i.e., the difference between the observed trends and summation. The unit is K/decade and that it needs longer time observations of Antarctic ozone recovery. In fact, the most recent observation shows that the Antarctic Ozone Hole in 2019 is one of the smallest ones. It rapidly decreased in middle September and disappeared in early November. The early disappearance of the Ozone Hole in 2019 might be due to natural dynamic variability, while it could also be a signature of the recovery of the Ozone Hole.

An important question is why planetary wave activity in the SH stratosphere has no longer increased in the recent decade. According to the analysis by $\mathrm{Hu}$ and $\mathrm{Fu}$ (2009) and Lin et al. (2012), stratospheric wave activity over 1979-2006 was enhanced because of SST warming over the tropical western Pacific Ocean. If it is true, the result here implies that SST over the tropical western Pacific has not been increased over 2007-2017, which is verified from observation. One possibility is that the Pacific Decadal Oscillation (PDO) has switched from the warm phase to the cool phase since the late 1990s. Whether it is the case requires future analysis and simulation studies.

It is worth noting that ozone recovery and the associated Antarctic stratospheric warming have important implications not only for stratospheric climate but also for tropospheric and surface climates. Recent works have showed that ozone recovery would lead to retreat of Antarctic sea ice, due to dynamic or radiative effects (Bitz and Polvani 2012; Xia et al. 2019). It would also cause the SH Hadley cell narrowed (Hu et al. 2018; Tao et al. 2016). These all would cause consequent surface climate changes on $\mathrm{SH}$. 

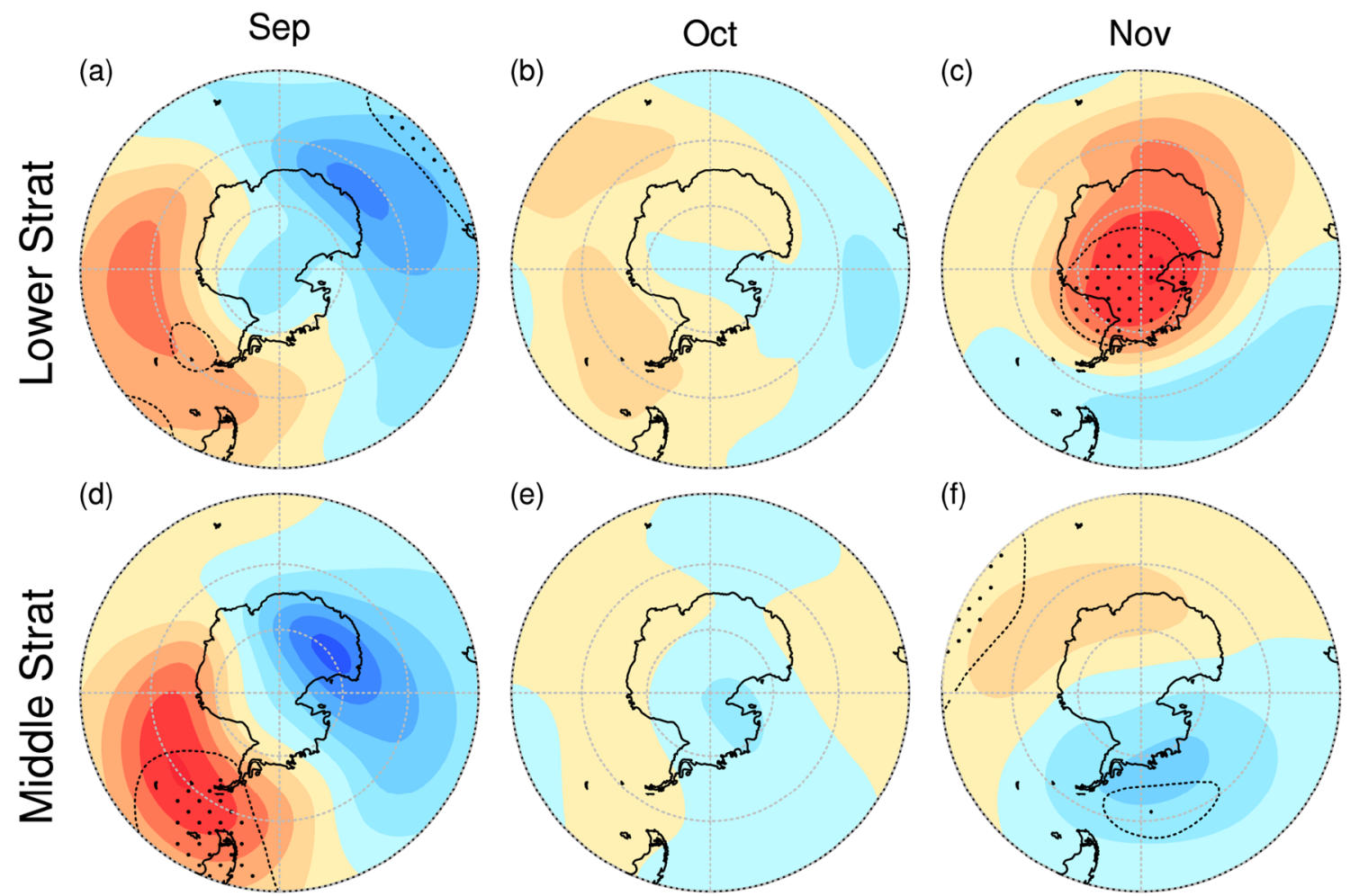

(e)

(f)
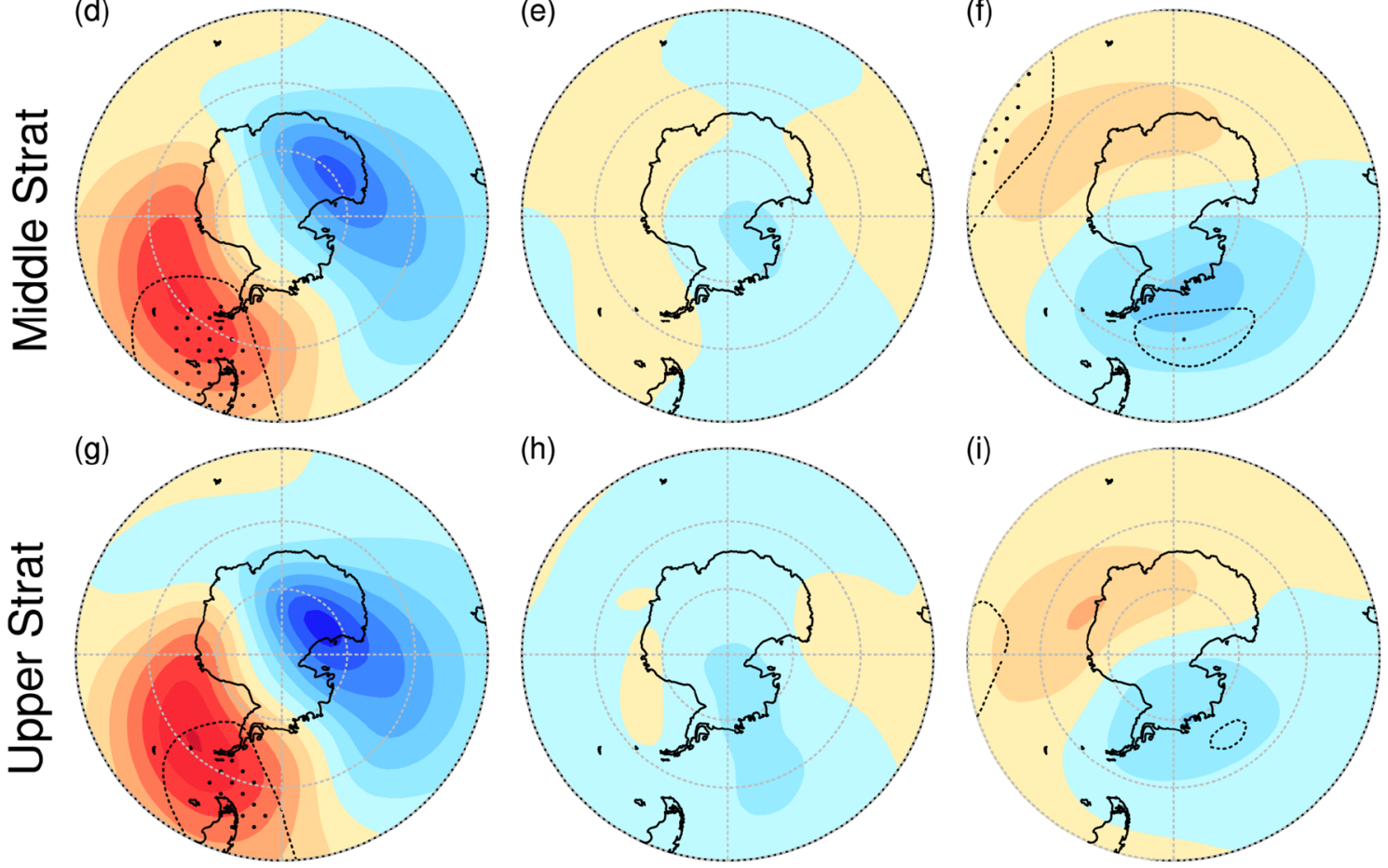

(i)

(k)
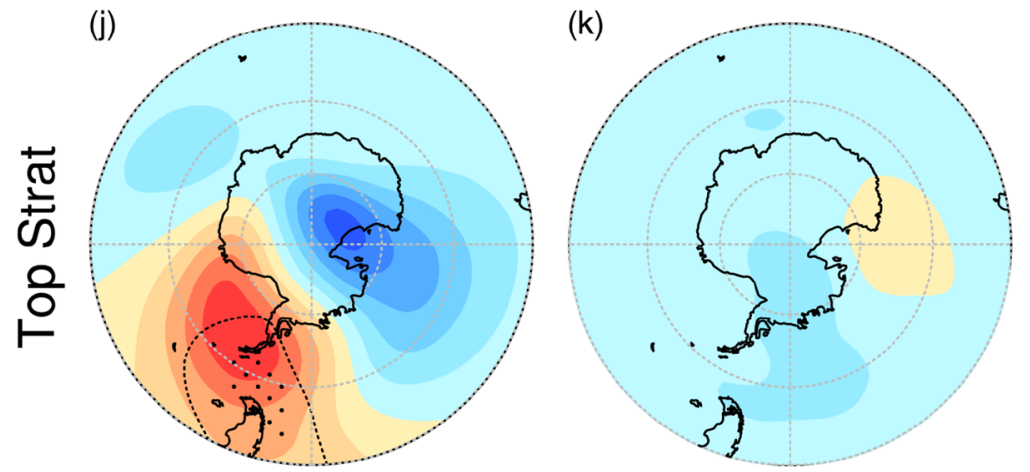

(I)
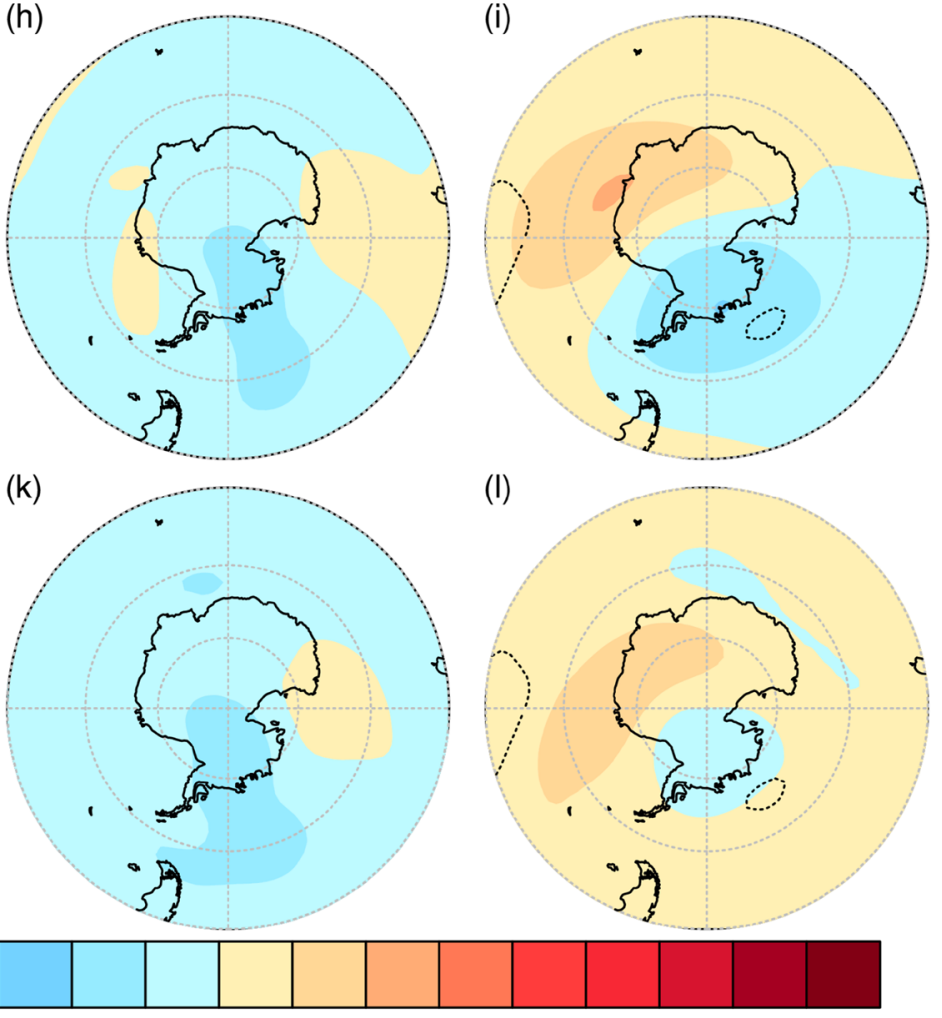

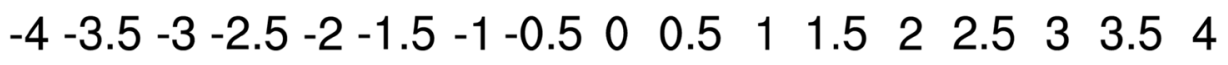

Fig. 8 Simulated spatial distributions of stratospheric temperature responses to ozone changes over 2007-2017. Panels from top to bottom are temperature responses in TLS, TMS, TUS, and TTS, respec- tively. From left to right, the panels are for September, October, and November, respectively. Color interval is $0.5 \mathrm{~K}$ 
Acknowledgements We thank Dr. Jian Yue for helpful comments. The data used in this paper are listed in the references, figures, and tables. This work is supported by the National Natural Science Foundation of China (NSFC), under Grants 41530423 and 41761144072 . Y. Xia is also supported by grants from the China Postdoctoral Science Foundation (2018M630027)

Open Access This article is licensed under a Creative Commons Attribution 4.0 International License, which permits use, sharing, adaptation, distribution and reproduction in any medium or format, as long as you give appropriate credit to the original author(s) and the source, provide a link to the Creative Commons licence, and indicate if changes were made. The images or other third party material in this article are included in the article's Creative Commons licence, unless indicated otherwise in a credit line to the material. If material is not included in the article's Creative Commons licence and your intended use is not permitted by statutory regulation or exceeds the permitted use, you will need to obtain permission directly from the copyright holder. To view a copy of this licence, visit http://creativecommons.org/licenses/by/4.0/.

\section{References}

Andrews DG, Holton JR, Leovy CB (1987) Middle atmosphere dynamics. Academic Press, Cambridge

Bitz CM, Polvani LM (2012) Antarctic climate response to stratospheric ozone depletion in a fine resolution ocean climate model. Geophys Res Lett 39:L20705

Dee DP, Uppala SM, Simmons AJ, Berrisford P, Poli P, Kobayashi S, Andrae U, Balmaseda MA, Balsamo G, Bauer P, Bechtold P, Beljaars ACM, van de Berg L, Bidlot J, Bormann N, Delsol C, Dragani R, Fuentes M, Geer AJ, Haimberger L, Healy SB, Hersbach H, Holm EV, Isaksen L, Kallberg P, Kohler M, Matricardi M, McNally AP, Monge-Sanz BM, Morcrette JJ, Park BK, Peubey C, de Rosnay P, Tavolato C, Thepaut JN, Vitart F (2011) The ERA-Interim reanalysis: configuration and performance of the data assimilation system. Q J Roy Meteor Soc 137:553-597

Eyring V, Harris NRP, Rex M, Shepherd TG, Fahey DW, Amanatidis GT, Austin J, Chipperfield MP, Dameris M, Forster PMDF, Gettelman A, Graf HF, Nagashima T, Newman PA, Pawson S, Prather MJ, Pyle JA, Salawitch RJ, Santer BD, Waugh DW (2005) A strategy for process-oriented validation of coupled chemistryclimate models. B Am Meteorol Soc 86:1117-1134

Eyring V, Cionni I, Bodeker GE, Charlton-Perez AJ, Kinnison DE, Scinocca JF, Waugh DW, Akiyoshi H, Bekki S, Chipperfield MP, Dameris M, Dhomse S, Frith SM, Garny H, Gettelman A, Kubin A, Langematz U, Mancini E, Marchand M, Nakamura T, Oman LD, Pawson S, Pitari G, Plummer DA, Rozanov E, Shepherd TG, Shibata K, Tian W, Braesicke P, Hardiman SC, Lamarque JF, Morgenstern O, Pyle JA, Smale D, Yamashita Y (2010) Multimodel assessment of stratospheric ozone return dates and ozone recovery in CCMVal-2 models. Atmos Chem Phys 10:9451-9472

Fu Q, Solomon S, Lin P (2010) On the seasonal dependence of tropical lower-stratospheric temperature trends. Atmos Chem Phys 10:2643-2653

Fu Q, Lin P, Solomon S, Hartmann DL (2015) Observational evidence of strengthening of the Brewer-Dobson circulation since 1980. J Geophys Res-Atmos 120:10214-10228

Hu Y, Fu Q (2009) Stratospheric warming in Southern Hemisphere high latitudes since 1979. Atmos Chem Phys 9:4329-4340

$\mathrm{Hu}$ Y, Tung KK (2002) Interannual and decadal variations of planetary wave activity, stratospheric cooling, and Northern Hemisphere Annular mode. J Clim 15:1659-1673
Hu Y, Huang H, Zhou C (2018) Widening and weakening of the Hadley circulation under global warming. Sci Bull 63:640-644

Johanson CM, Fu Q (2007) Antarctic atmospheric temperature trend patterns from satellite observations. Geophys Res Lett 34:L12703

Langematz U, Kunze M, Krüger K, Labitzke K, Roff GL (2003) Thermal and dynamical changes of the stratosphere since 1979 and their link to ozone and $\mathrm{CO}_{2}$ changes. J Geophys Res 108:ACL 9-1-ACL 9-13

Lin P, Fu Q, Solomon S, Wallace JM (2009) Temperature trend patterns in southern hemisphere high latitudes: novel indicators of stratospheric change. J Clim 22:6325-6341

Lin P, Fu Q, Hartmann DL (2012) Impact of tropical SST on stratospheric planetary waves in the Southern Hemisphere. J Clim 25:5030-5046

Marsh DR, Mills MJ, Kinnison DE, Lamarque J-F, Calvo N, Polvani LM (2013) Climate change from 1850 to 2005 simulated in CESM1(WACCM). J Clim 26:7372-7391

Maycock AC, Randel WJ, Steiner AK, Karpechko AY, Christy J, Saunders R, Thompson DWJ, Zou C-Z, Chrysanthou A, Luke Abraham N, Akiyoshi H, Archibald AT, Butchart N, Chipperfield M, Dameris M, Deushi M, Dhomse S, Di Genova G, Jöckel P, Kinnison DE, Kirner O, Ladstädter F, Michou M, Morgenstern O, O'Connor F, Oman L, Pitari G, Plummer DA, Revell LE, Rozanov E, Stenke A, Visioni D, Yamashita Y, Zeng G (2018) Revisiting the mystery of recent stratospheric temperature trends. Geophys Res Lett 45:9919-9933

Mears CA, Wentz FJ (2009) Construction of the remote sensing Systems V3.2 atmospheric temperature records from the MSU and AMSU microwave sounders. J Atmos Ocean Technol 26:1040-1056

Philipona R, Mears C, Fujiwara M, Jeannet P, Thorne P, Bodeker G, Haimberger L, Hervo M, Popp C, Romanens G, Steinbrecht W, Stübi R, Van Malderen R (2018) Radiosondes show that after decades of cooling the lower stratosphere is now warming. J Geophys Res 123(22): 12-509

Ramaswamy V, Schwarzkopf MD, Randel WJ (1996) Fingerprint of ozone depletion in the spatial and temporal pattern of recent lower-stratospheric cooling. Nature 382:616-618

Ramaswamy V, Chanin M-L, Angell J, Barnett J, Gaffen D, Gelman M, Keckhut P, Koshelkov Y, Labitzke K, Lin J-JR, O’Neill A, Nash J, Randel W, Rood R, Shine K, Shiotani M, Swinbank R (2001) Stratospheric temperature trends: observations and model simulations. Rev Geophys 39:71-122

Randel WJ, Wu F (1999) A stratospheric ozone trends data set for global modeling studies. Geophys Res Lett 26:3089-3092

Randel WJ, Polvani L, Wu F, Kinnison DE, Zou C-Z, Mears C (2017) Troposphere-stratosphere temperature trends derived from satellite data compared with ensemble simulations from WACCM. J Geophys Res 122:9651-9667

Salby M, Titova E, Deschamps L (2011) Rebound of Antarctic ozone. Geophys Res Lett 38:L09702

Smith KL, Neely RR, Marsh DR, Polvani LM (2014) The specified chemistry whole atmosphere community climate model (SCWACCM). J Adv Model Earth Syst 6:883-901

Solomon S (1999) Stratospheric ozone depletion: a review of concepts and history. Rev Geophys 37:275-316

Solomon S, Ivy DJ, Kinnison D, Mills MJ, Neely RR, Schmidt A (2016) Emergence of healing in the Antarctic ozone layer. Science 353:6296

Solomon S, Ivy D, Gupta M, Bandoro J, Santer B, Fu Q, Lin P, Garcia RR, Kinnison D, Mills M (2017) Mirrored changes in Antarctic ozone and stratospheric temperature in the late 20th versus early 21st centuries. J Geophys Res 122:8940-8950

Tao LJ, Hu YY, Liu JP (2016) Anthropogenic forcing on the Hadley circulation in CMIP5 simulations. Clim Dyn 46:3337-3350 
Thompson DWJ, Solomon S (2002) Interpretation of recent southern hemisphere climate change. Science 296:895-899

Thompson DWJ, Seidel DJ, Randel WJ, Zou C-Z, Butler AH, Mears C, Osso A, Long C, Lin R (2012) The mystery of recent stratospheric temperature trends. Nature 491:692

Van Der AR, Allaart M, Eskes H (2015a) Multi-Sensor Reanalysis (MSR) of total ozone, vol 2. Royal Netherlands Meteorological Institute (KNMI), De Bilt

Van Der ARJ, Allaart MAF, Eskes HJ (2015b) Extended and refined multi sensor reanalysis of total ozone for the period 1970-2012. Atmos Meas Tech 8:3021-3035

Wespes C, Hurtmans D, Chabrillat S, Ronsmans G, Clerbaux C, Coheur PF (2019) Is the recovery of stratospheric $\mathrm{O}_{3}$ speeding up in the Southern Hemisphere? An evaluation from the first IASI decadal record (2008-2017). Atmos Chem Phys 19:14031-14056

WMO (World Meteorological Organization) (2018) Scientific assessment of ozone depletion: 2018, Global ozone research and monitoring project-report no. 58 . Geneva, Switzerland, 588 pp
Xia Y, Hu Y, Liu J, Huang Y, Xie F, Lin J (2019) Stratospheric ozoneinduced cloud radiative effects on Antarctic sea ice. Adv Atmos, Sci, p 37

Young PJ, Thompson DWJ, Rosenlof KH, Solomon S, Lamarque J-F (2011) The seasonal cycle and interannual variability in stratospheric temperatures and links to the brewer-dobson circulation: an analysis of MSU and SSU data. J Clim 24:6243-6258

Zou C-Z, Qian H (2016) Stratospheric temperature climate data record from merged SSU and AMSU-A observations. J Atmos Ocean Technol 33:1967-1984

Publisher's Note Springer Nature remains neutral with regard to jurisdictional claims in published maps and institutional affiliations. 